\title{
QUIZLET: PENGGUNAAN APLIKASI SMARTPHONE UNTUK SISWA DALAM MENDUKUNG MOBILE LEARNING ${ }^{2}$
}

\author{
Eric Kunto Aribowo \\ Universitas Widya Dharma Klaten \\ erickunto@unwidha.ac.id
}

\begin{abstract}
In our ever-changing marketplace, today's students are being educated, largely, for jobs that haven't yet been invented. Technology is being created and updated at a frenetic pace, and growing more pervasive and useful with each stride. As schools face dwindling resources and higher stakes than ever, does mobile technology hold the key to improving the educational system and reengaging students? Mobile technology offers a plethora offeatures and benefits that enable it to break the educational system wide open, engaging students in new ways and making educational experiences more meaningful, if schools can effectively utilize structured, integrated approaches for implementation of this new technology. The main goal of this paper is to suggest Quizlet that it can be used to transform the mobile learning solution in a developing country.
\end{abstract}

Keywords: mobile learning, mobile apps, Quizlet

\section{Pendahuluan}

Minat masyarakat Indonesia terhadap kemajuan teknologi, khususnya smartphone mengalami pertumbuhan yang signifikan. Laporan dari riset GfK yang mendata trafik penjualan mulai Januari hingga Juni 2015 menyebutkan bahwa: "Indonesia mengalami kenaikan penjualan sebanyak 27 persen sebanyak 14,9 juta unit"3. Hal ini menjadikan Indonesia sebagai pasar terbesar di Asia Tenggara disusul Thailand dan Vietnam. Menurut hasil survei yang dilakukan Google, Inc. melalui consumerbarometer.com ${ }^{4}$ masyarakat pengguna smartphone di Indonesia mayoritas diisi oleh golongan usia di bawah 24 tahun (dengan responden sebanyak 2283 orang) secara mayoritas memanfaatkan smartphone mereka untuk mendengarkan musik (93\%), memotret dan merekam video (89\%), bermain games (73\%), menunjukkan waktu $(67 \%)$, menyetel alarm $(33 \%)$, membaca berita (34\%), mengakses peta/navigasi $(18 \%)$, mengatur janji/diari $(11 \%)$, mengecek cuaca (6\%), merekam aktivitas kesehatan (6\%), membuat daftar belanja (6\%), serta membaca buku/majalah (5\%).

Ketertarikan remaja di Indonesia terhadap smartphone sayangnya sebagian besar masih diperuntukkan dalam aktivitas hiburan, belum mengarah pada kegiatan yang lebih produktif terutama dalam

\footnotetext{
${ }^{1}$ Quizlet, baik website maupun aplikasi yang terdapat di iOS dan Android merupakan produk terobosan teknologi yang membuat proses belajar menjadi lebih menyenangkan, ringkas, dan akhirnya lebih produktif. Pada bentuknya yang paling dasar, quizlet sebenarnya tidak semata-mata merupakan sebuah flashcard, melainkan sebuah permainan kata, berbagi fail, dan mampu merekam kelas menjadi sebuah komponen yang lebih terorganisasi daripada hanya sekedar aplikasi.

${ }^{2}$ Aribowo, E. K. (2015) “Quizlet: Penggunaan Aplikasi Smartphone untuk Siswa dalam Mendukung Mobile Learning," in Seminar Nasional Pendidikan Bahasa Indonesia. Surakarta, hal. 31-38.

${ }^{3}$ Disalin dari tulisan Siti Sarifah Alia (2015) dengan judul "Indonesia Pasar Smartphone Terbesar di Asia Tenggara” yang dimuat dalam http://teknologi.news.viva.co.id diupdate Kamis, 3 September 2015.

${ }^{4}$ Perangkat baru milik Google, Inc. yang menyediakan data mengenai penggunaan internet di seluruh dunia serta dapat mengukur selera dan penggunaan konsumen terhadap berbagai konten yang ada.
} 
hal pendidikan -bandingkan dengan pemanfaatan smartphone yang dilakukan di Stockton, New Jersey yang telah merambah sebagai perangkat pembelajaran e-learning, mengunduh podcast, menerima dan mengirim surel (Foti dan Jomayra, 2014: 65). Padahal, melalui smartphone para pendidik memiliki kesempatan besar untuk menyuguhkan pengalaman-pengalaman edukatif yang baru kepada anak didiknya.

Meskipun dalam beberapa tahun terakhir kaum pendidik telah mengusung produk-produk teknologi masuk ke kelas-kelas -mayoritas menggunakan perangkat komputer khususnya laptop-, tetapi adopsi teknologi tersebut dirasa sangat lambat apabila dibandingkan dengan munculnya perangkat mobile lain seperti smartphone dan tablet sebagaimana disebut Doerr (2014). Faktanya, saat ini, perhatian dunia pendidikan mulai bergeser ke arah perangkat mobile (lihat Vargas, 2011; Foti dan Jomayra, 2014; Ashcroft dan Imrie, 2014; Srithar dan Dhivya, 2015; Davie dan Tobias, 2015). Imbasnya nyata. Doerr (2014) menyatakan: "di tahun 2014 setidaknya terdapat 75 o juta aplikasi edukatif yang dapat di-install (dipasang) untuk perangkat mobile".

Mengabaikan mobile learning karena memiliki potensi sebagai distraction (pengganggu) atau memunculkan penyalahgunaannya berarti menghilangkan kesempatan masyarakat untuk mencari dan menggunakan sumber informasi yang tanpa batas melalui ujung jari mereka. Teknologi mobile menyuguhkan kans yang besar untuk merevolusi sistem pendidikan dan pembelajaran apabila para guru dan penyelenggara pendidikan yang berwawasan luas, kreatif, dan open-minded mau menganutnya. Sudah selayaknya kita berkomitmen untuk memanfaatkan teknologi terbaik yang tersedia untuk membantu kita dalam rangka mengembangkan diri dan memberikan anak didik kita pengalaman-pengalaman terbaik dalam belajar guna menyiapkan mereka kelak ke dunia nyata.

\section{Di Balik Beberapa Sisi Positif Mobile Learning}

Kukulska-Hulme dan John (2005: 1) yang merupakan pionir sistem pembelajaran ini mengawali definisinya mengenai mobile learning dengan batasan "the possibilities opened up by portable, lightweight devices that are sometimes small enough to fit in a pocket or in the palm of one's hand". Ini berarti bahwa yang tergolong dalam perangkat ini termasuk telepon genggam (baik ponsel maupun handphone), smartphone, palmtop, Personal Digital Assistant (PDA), PC tablet, komputer laptop, dan pemutar media personal. Perangkatperangkat tersebut dapat digunakan untuk mempermudah guru dan siswa dalam berkomunikasi dan berkolaborasi, serta menciptakan aktivitas pembelajaran yang berbeda dari apa yang dapat dilakukan melalui media lain. Artinya, perangkat mobile seperti smartphone dapat membuat pembelajaran menjadi portabel, spontan, personal, dan menarik5. Secara lebih umum, McQuiggan, dkk. (2015: 8) menawarkan definisi mobile learning sebagai

"the experience and opportunity afforded by the evolution of educational technologies. It is anywhere, anytime learning enabled by instant, on-demand access to a personalized world filled with the tools and resources we prefer for creating our own knowledge, satisfying our curiosities, collaborating with others, and cultivating experiences otherwise unattainable."

\footnotetext{
${ }^{5}$ Sebagai perbandingan baca Aribowo (2014) tentang pemanfaatan perangkat mobile, khususnya iPad dalam pembelajaran bahasa.
} 
Pernyataan tersebut mengisyaratkan bahwa mobile learning berarti mengadaptasi dan membangun kemajuan melalui teknologi mobile terbaru, mendefinisikan ulang tanggungjawab para guru dan siswa, serta mengaburkan batas di antara pembelajaran formal dan informal. Hal ini mencakup pemahaman tentang bagaimana menjadi seorang lifelong learner dan bagaimana dapat berhasil dalam dunia kerja saat ini.

Mobile learning bukan merupakan obat mujarab untuk semua permasalahan yang mengganggu sistem pendidikan kita. Dalam hal ini, kami tidak menyarankan hanya dengan memegang perangkat mobile seseorang menyangka secara serta-merta akan terjadi peningkatan prestasi dan antusiame belajar. Seperti halnya komputer yang telah hadir sebelumnya, perangkat mobile seperti smartphone memiliki potensi yang sangat dahsyat untuk mengubah cara belajar siswa dan harapan kita tentang apa yang harus terjadi di dalam ruang kelas. Kemampuan perangkat mobile untuk memberi "efek kejut" terhadap status quo sistem pendidikan dan memperbaruinya tergantung pada pengajaran yang telah dirajut. Hal ini tergantung kepada pikiran terbuka dan kreativitas yang dimiliki oleh guru serta kesiapan untuk mengintegrasikannya dalam kurikulum, dana, dan budaya untuk memungkinkan perangkat tersebut berada di tangan siswa didik, serta inovasi yang berkelanjutan agar perangkat tersebut senantiasa tetap digunakan secara efektif. Selanjutnya, hal ini melarang kita pula untuk berasumsi bahwa digital natives ${ }^{6}$-meskipun mereka mahir dengan teknologi- mengetahui bagaimana menggunakan perangkat mobile untuk keperluan pendidikan tanpa adanya pelatihan. Sebagaimana halnya guru-guru, penyelenggara pendidikan, dan orang tua mereka; mereka pun membutuhkan arahan mengenai bagaimana belajar dengan menggunakan teknologi pendidikan yang baru.

Mobile learning menawarkan berbagai macam keuntungan yang dapat diraih siswa dalam berbagai cara serta untuk meningkatkan pendidikan yang mereka dapatkan. Keuntungan terbesar pertama adalah kemampuan untuk belajar kapanpun dan di manapun sebagaimana disebutkan oleh Foti dan Jomayra (2014: 59). Secara tradisional, duduk di dalam ruang kelas antara jam o7.0o hingga 14.0o merupakan anggapan di mana dan kapan mereka harus belajar. Tentunya, belajar tidaklah terbatas pada lokasi dan waktu tertentu. Aktivitas belajar dapat terjadi kapan pun dan di mana pun dengan menggunakan perangkat mobile. Kedua, smartphone dan perangkat lain yang terhubung dengan internet telah menjalar menjadi budaya kita, sehingga dunia pendidikan tentunya tidak akan tertatih-tatih bilamana teknologi ini diimplementasikan ke dalam proses kegiatan belajar mengajar. Ketiga, perangkat mobile belakangan menjadi sebuah produk yang terjangkau. Produsen telah menawarkan berbagai macam produk dengan harga yang terjangkau bagi masyarakat. Keempat, mobile learning menyuguhkan sebuah media yang mampu meningkatkan kemampuan berpikir tingkat tinggi. 21st Century Skills yang menjadi kemampuan yang harus dikuasai siswa di sekolah seperti: berpikir kritis dan problem solving, berkomunikasi, berkolaborasi, berkreasi dan berinovasi merupakan contoh-contoh aktivitas implisit yang terdapat dalam penggunaan sehari-hari teknologi pendidikan melalui perangkat mobile.

Dalam pada itu, mobile learning menawarkan cara baru untuk memotivasi siswa dengan menyediakan keterlibatan dan kebaruan tingkat tinggi, personalisasi, dan kemandirian. Kemampuan untuk terus menggunakan aplikasi baru dan menemukan cara baru untuk menggunakan perangkat ini menjadi aktivitas yang menantang dan menarik bagi siswa. Penggunaan smartphone sebagai perangkat mobile memiliki level yang tinggi di kalangan siswa, khususnya anak-anak dan remaja, dan merupakan suatu hal yang bernilai

\footnotetext{
${ }^{6}$ Seseorang yang lahir atau beranjak dewasa jelang era teknologi digital. Mereka ini telah familiar dengan komputer dan internet sejak usia dini.
} 
tentunya apabila mempertemukan mereka kepada mobile learning daripada membatasi mereka untuk metode pembelajaran yang lebih tua, ketika mereka jelas memiliki bakat dan gairah terhadap teknologi yang lebih baru. Mengizinkan dan mendorong penggunaan smartphone untuk tujuan akademik memberikan arti dan semangat baru untuk pelajaran.

Akhirnya, rencana mobile learning yang kuat tidak dapat berfungsi tanpa aplikasi yang bagus untuk kerangka pelajaran. Guru harus mencari cara untuk mencari konten dan perangkat pembelajaran yang baik, dan bagaimana untuk memasukkannya ke dalam kurikulum dan RPP. Demikian pula, pengembang aplikasi harus fokus pada mengatasi kebutuhan pengguna dan menyesuaikan pengembangan aplikasi untuk pasar pendidikan. Aplikasi pendidikan terbaik menyajikan informasi yang diperlukan dengan cara "segar" dan selaras dengan kebutuhan sekolah. Pada intinya, mengembangkan aplikasi pendidikan yang berkualitas tidak hanya membuat peralihan dari buku teks menjadi sebuah ebook. Aplikasi pendidikan yang baik, seperti semua bagian dari mobile learning, memerlukan keseimbangan untuk membuat mereka dapat berinteraksi secara tepat sekaligus berdampak. Melalui tulisan ini, kami menawarkan sebuah contoh aplikasi pendidikan yang baik dan dapat diadaptasikan ke dalam pembelajaran di ruang-ruang kelas.

\section{Quizlet: Selayang Pandang serta Keunggulannya dalam Dunia Pendidikan}

Quizlet merupakan perangkat pembelajaran daring (online) yang dikembangkan oleh seorang siswa sekolah menengah atas di California yang bernama Andrew Sutherland. Ide pengembangan perangkat ini berasal dari pengalaman pribadinya ketika diminta untuk mengingat 111 nama-nama hewan oleh guru bahasa Perancis. Hadirnya Quizlet sebenarnya tidak terhitung baru karena perangkat ini mula-mula dirancang pada tahun 2005, namun kemudian dirilis ke publik pada bulan Januari 2007 dalam bentuk website. Selanjutnya, pada bulan Agustus 2012 Quizlet dirilis dalam bentuk aplikasi mobile untuk iOS yang kemudian setahun berikutnya disusul aplikasi untuk Android pada bulan Agustus 2013.

Seketika Quizlet menjelma sebagai perangkat sederhana yang mudah digunakan serta inovatif yang dapat membantu jutaan siswa remaja untuk belajar -disebutkan lebih dari 20 juta pengguna aktif di setiap bulan yang mengunjungi Quizlet, baik melalui website maupun aplikasi ${ }^{8}$. Aplikasi ini mudah digunakan untuk segala usia, mulai dari sekolah dasar hingga perguruan tinggi (Vargas, 2011; Foti dan Jomayra, 2014; Davie dan Tobias, 2015). Mereka dapat mengolah dan mengoptimalkan aplikasi ini untuk tujuan belajar.

Sebagai perangkat yang difungsikan untuk meningkatkan kemampuan menghafal, Quizlet memperkenankan pengguna untuk dapat membuat sekumpulan kartu -yang seringkali dalam dunia pendidikan dikenal dengan sebutan flashcard- yang terdiri dari istilah (term) dan definisi (definition) yang dapat disesuaikan dengan kebutuhan masing-masing individu. Selanjutnya, pengguna dapat dengan segera berinteraksi, bekerja sama, dan berbagi flashcard. Membuat flashcard dapat dimulai dari awal atau dengan mengedit set kartu yang sudah tersedia.

Kalau tidak salah, Quizlet merupakan salah satu website edukasi terbesar di dunia. Pada dasarnya, akses kepada perangkat ini tidak dipungut biaya atau gratis, baik dalam bentuk website atau aplikasi. Untuk itu,

\footnotetext{
${ }^{7}$ Quizlet dapat diakses melalui daring https://quizlet.com. Adapun untuk aplikasi mobile dapat diunduh melalui toko daring yang menyediakan konten digital (untuk iOS melalui App Store, sedangkan untuk Android melalui Google Play dengan memasukkan kata kunci "Quizlet").

${ }^{8}$ berdasarkan data yang diambil dari www.quizlet.com/jobs/data-scientist
} 
keterjangkauan terhadap perangkat ini tidak perlu diragukan lagi. Meskipun tersedia dalam bentuk aplikasi smartphone, aplikasi ini juga dapat digunakan meskipun dalam keadaan offline (tidak terhubung dengan internet).

Meskipun perangkat ini dapat diakses secara gratis, namun perangkat ini telah terorganisasi dengan baik. Dengan kata lain, fasilitas yang diberikan untuk menyediakan layanan kelas virtual mulai dari mengelola beberapa folder yang berisi sekumpulan flashcard dalam satu topik atau materi tertentu, memberikan batasan kepada anggota pengguna (apakah semua orang, kelas tertentu, hanya saya, atau membutuhkan password tertentu) untuk mengaksesnya, hingga merekam skor para pengguna ketika menjalankan mode-mode yang ada. Bahkan, serangkaian flashcard yang telah dibuat dapat dicetak, termasuk tes.

Sebagai layanan pendukung dan sarana mempermudah mengingat, Quizlet menyediakan fasilitas yang dilengkapi audio-visual. Artinya, pengguna dapat menyimak pelafalan kata yang ada sekaligus memperhatikan gambar ketika flashcard dimainkan. Di samping itu, dengan melakukan upgrade akun sebesar \$24,99 untuk satu tahun (\$39,99 untuk 2 tahun dan $\$ 49,99$ untuk 3 tahun) para guru dapat merekam suaranya sehingga para siswa dapat mendengarnya di manapun mereka berada.

Pada hakikatnya, fungsi utama Quizlet memang digunakan untuk mengembangkan kecerdasan linguistik, terutama dalam hal memperkaya kosakata. Akan tetapi, pada faktanya Quizlet dapat digunakan untuk melatih empat keterampilan berbahasa termasuk di dalamnya menyimak, berbicara, membaca, dan menulis. Keterampilan menyimak dapat dilatih ketika pengguna mendengarkan audio yang berisi definisi atau istilah tertentu pada mode speller, berbicara terjadi ketika pengguna mengulang kembali kata-kata yang telah dilafalkan melalui flashcard, membaca dilakukan ketika pengguna memainkan mode scatter dan space race dengan membaca tulisan yang terdapat dalam flashcard, dan menulis dimanfaatkan ketika menggunakan mode learn, speller, test, dan space race melalui praktik mengetik jawaban dengan ejaan yang benar.

Tambahan pula, bahwa Quizlet mendukung berbagai bahasa, termasuk tulisan. Selain bahasa-bahasa mayoritas seperti bahasa Inggris, Spanyol, Perancis, Italia, Jerman, Rusia, Jepang, China, Korea, dan Latin; Quizlet mendukung lebih kurang 145 bahasa di dunia, termasuk bahasa Indonesia, Sunda, Melayu, dan Arab. Bahkan, simbol matematis dan fonetis IPA-pun dapat dibubuhkan dalam flashcard.

Sebagai salah satu media pembelajaran yang menarik dan atraktif, tersedia berbagai cara flashcard digital dalam Quizlet ini digunakan. (a) Cards yang merupakan mode yang mirip dengan flashcard konvensional yang terbuat dari kertas. Di dalamnya, pengguna akan ditunjukkan masing-masing kartu yang terdiri dari istilah-istilah yang ada. Pengguna juga dapat membalikkan kartu dengan jalan menyentuh layar guna melihat definisi dari istilah tersebut. (b) Learn, memperkenankan pengguna untuk mengetik istilah dari definisi yang ditampilkan, begitu pula sebaliknya. Setelah mengetikkan jawaban, pengguna dapat mengetahui apakah jawabannya benar atau keliru. Kemudian secara otomatis dapat diketahui skor dari jawaban tersebut. (c) Speller, yang dapat digunakan untuk menyimak istilah yang diucapkan kemudian pengguna diharuskan untuk menuliskan ejaannya dengan benar. (d) Test, memungkinkan pengguna untuk mengambil tes dengan membubuhkan jawaban. Setidaknya tersedia empat metode (menuliskan jawaban, memasangkan, pilihan ganda, dan benar/salah) yang dapat dipilih dalam tes ini. Menariknya lagi, pengguna dapat mencetak (print)

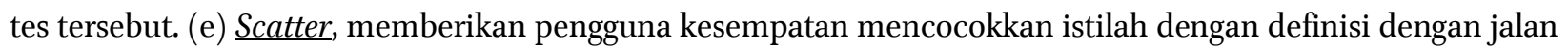
menyeret istilah kemudian menumpuknya ke definisi yang benar. Pasangan yang benar kemudian akan menghilang. Akhirnya, pengguna diminta untuk membersihkan layar dengan waktu secepat mungkin. (f) 
Space Race, ialah mode yang mengharuskan pengguna untuk mengetik istilah ketika definisi berjalan dari layar sebelah kiri ke sebelah kanan. Pengguna diharuskan mengetik jawaban yang benar sebelum definisi tiba di akhir layar. Terdapat kenaikan "level" dan nyawa apabila pengguna telah mencapai skor tertentu. Di samping itu, nyawa pun akan berkurang bilamana pengguna tidak mampu menjawab dengan tepat jawaban yang dibutuhkan. Keenam mode ini dapat dipilih apabila pengguna mengakses melalui website, sedangkan yang tersedia pada aplikasi untuk versi perangkat mobile diringkas hanya dengan tiga mode (cards, learn, dan match) yang fungsinya tidak jauh berbeda dengan apa yang terdapat di website.

\section{Quizlet sebagai Media Pembelajaran Alternatif dalam Mobile Learning}

Setelah memaparkan secara panjang lebar mengenai Quizlet, pada bagian ini kami ingin memberikan saran mengenai berbagai macam cara yang dapat ditempuh guna mentransformasi metode belajar dan pembelajaran melalui aplikasi yang terdapat dalam smartphone. Cara-cara berikut hanya sebagian kecil alternatif yang dapat dilakukan oleh para guru di sekolah masing-masing. Oleh karenanya, tidak menutup kemungkinan masih banyak cara-cara yang lebih kreatif dan inovatif dari penggunaan Quizlet sebagai sarana pendukung siswa menuju mobile learning.

\subsection{Model Pembelajaran Tebak Kata}

Flashcard memang dapat digunakan untuk apa saja. Seringnya, flashcard digunakan untuk bermain tebak-tebakan di antara penggunanya, antara lain untuk mengenal benda, kosakata, permainan ingatan, hingga untuk belajar membaca. Fungsi dasar flashcard tersebut juga dapat dilakukan melalui aplikasi Quizlet ini.

Model pembelajaran yang dapat dilakukan adalah model Tebak Kata. Dengan metode ini, guru dapat membagi siswanya berpasang-pasangan (atau berkelompok). Setelah memberikan arahan (mendiskusikan waktu atau jumlah kartu yang harus dijawab dalam permainan ini, misalnya), guru meminta para siswa untuk berdiri berpasang-pasangan. Seorang siswa yang membawa smartphone membacakan kata-kata yang tertulis di dalam kartu Quizlet kepada pasangannya, sementara pasangannya menebak jawaban yang dimaksud (dapat menggunakan mode cards). Pasangan siswa diperbolehkan duduk setelah menjawab dengan benar semua jawaban sesuai yang tertulis di kartu. Siswa juga diperbolehkan mengarahkan dengan kata-kata lain, asalkan bukan jawabannya.

Di samping itu, guru juga dapat mengadaptasi model-model pembelajaran yang telah ada seperti memberikan contoh kasus dengan model examples non examples; pembelajaran dengan berpasangan semisal think, pair, and share (TPS), pembelajaran dengan berkelompok seperti cooperative script dan student teamsachievement divisions (STAD) sesuai dengan kondisi siswa masing-masing.

\subsection{Self-direct Learning melalui Flashcard Digital}

Para siswa selayaknya diberikan motivasi untuk belajar dengan konsep mereka sendiri. Tujuan belajar dapat diatur dengan self-direct learning, yakni "a process in which individuals take the initiative, with or without help of others" (Srithar dan Dhivya, 2015: 217). Dengan demikian, para guru dapat mendiagnosa kebutuhan belajar mereka, memformulasikan tujuan pembelajaran, mengidentifikasi sumber-sumber pembelajaran, dan mengevaluasi hasil pembelajaran. 
Pada umumnya, flashcard merupakan sekumpulan kartu yang menghimpun informasi, baik dalam bentuk kata maupun angka, atau kombinasi keduanya. Flashcard dapat membantu keterlibatan siswa dalam mengingat kembali (recall) konsep-konsep yang dilakukan melalui pengalaman belajar secara mandiri. Flashcard mampu memberikan umpan balik (feedback) seketika pengguna berhasil menyelesaikan serangkaian pertanyaan yang membantu siswa dalam meningkatkan belajar mereka tentang konsep-konsep atau ide-ide tertentu. Ide-ide tersebut dapat diolah kembali oleh siswa dengan caranya sendiri. Hal yang terbaik adalah ketika siswa dapat membuat flashcard dengan menggunakan kata-katanya sendiri agar lebih mudah dipahami. Selain itu, ini berarti akan memperbanyak koleksi flashcard yang ada ketika siswa mau membaginya kepada orang lain. Dalam konteks ini, akan diperoleh efek yang signifikan dan positif mengenai kemajuan di antara siswa dalam memahami dan mempelajari topik-topik yang dibahas.

Self-direct learning menggunakan Quizlet dapat dilakukan dengan memanfaatkan mode cards, yang dapat berfungsi untuk menghafal dan menguji memori atau ingatan secara mandiri. Flashcard dapat diatur sehingga mampu berjalan (mengganti) kartu secara otomatis, baik secara berurutan maupun acak. Siswa dapat membubuhkan tanda bintang untuk memerikan fokus pada subjek yang kita kehendaki, misalnya pada istilah yang belum dikuasai.

\subsection{Tes sebagai Evaluasi Diri Siswa}

Quizlet sebagai media evaluasi diri dapat ditempuh dengan meminta siswa memanfaatkan mode yang tersedia di Quizlet. Sebelumnya, guru mempersiapkan terlebih dahulu serangkaian kartu yang merupakan konsep kunci pada materi yang diajarkan ${ }^{9}$. Serangkaian kartu yang telah disiapkan kemudian dapat dimasukkan dalam sebuah kelas virtual. Guru dapat mengundang siswa dengan jalan memberikan tautan kepada para siswa agar dapat masuk ke kelas tersebut. Dengan cara lain, siswa juga dapat mencari kelas yang dimaksud pada fitur pencarian. Selanjutnya, guru sebagai pengelola kelas (admin) menerima (accept) permintaan para siswa yang ingin bergabung di kelas tersebut. Selanjutnya, guru meminta siswa untuk membuka smartphone serta memainkan kartu-kartu tersebut. Dalam konteks ini, dapat digunakan dua mode, yakni mode learn dan match.

Mode learn dapat digunakan untuk melatih ejaan. Pada mode ini siswa diminta untuk membubuhkan jawaban atau pasangan dari kartu yang muncul secara acak. Untuk menjawab dengan benar, siswa diharuskan mengetikkan ejaan dengan benar pula. Apabila terdapat kesalahan ejaan, akan terdapat pemberitahuan berwarna merah. Adapun warna hijau menandai jawaban yang benar. Setiap satu ronde terdapat maksimal tujuh kartu yang pada setiap akhir ronde akan muncul skor berupa hasil akhir persentase akurasi pengetikan, total istilah yang dikuasai, serta berapa kesalahan kata yang dilakukan.

Mode match merupakan salah satu fitur permainan yang ada dalam Quizlet. Mode ini bertujuan untuk memasangkan kartu dengan pasangannya yang tepat. Pada mode ini juga disediakan waktu penghitung (timer) sehingga siswa dapat mengetahui waktu yang dibutuhkan untuk menyelesaikan setiap sesi (6 pasang kartu). Dengan demikian, tercatat perolehan watu yang dihasilkan. Nilai terbaik (waktu tercepat) akan tercatat dan digunakan sebagai standar untuk percobaan berikutnya.

\footnotetext{
${ }^{9}$ Tersedia dua tipe akun, teacher dan student. Masing-masing akun memiliki fungsi masing-masing. Akan tetapi, untuk membuat flashcard dapat dilakukan dari kedua akun tersebut. Hanya saja, untuk mengelola kelas hanya dapat dilakukan apabila terdaftar sebagai akun teacher.
} 
Setelah siswa menjalankan mode tersebut, akumulasi hasil perolehan nilai seluruh siswa akan terekam dalam grafik yang terdapat dalam akun guru (pilih "flashcard" lalu pilih "tools" dan "scores"). Secara otomatis sistem akan mengurutkan perolehan siswa berdasarkan urutan tiga besar ${ }^{10}$. Guru dapat mengumumkan atau mencetak hasil tes tersebut sehingga siswa mengetahui hasil proses belajarnya. Tes sebagai salah satu metode evaluasi diri siswa ini tidak hanya dapat dilakukan di saat proses kegiatan belajar mengajar berlangsung, tetapi dapat pula dilakukan di luar sekolah. Oleh sebab itu, dukungan dan pengawasan dari pihak keluarga sangat dibutuhkan dalam rangka menciptakan lingkungan belajar yang kondusif.

\section{Penutup}

Penggunaan perangkat mobile, khususnya smartphone dalam kaitannya dengan mobile learning, dapat difungsikan untuk tujuan akademis maupun sebagai pendukung pembelajaran di ruang kelas. Aplikasi Quizlet dapat diunduh dan dipasang ke dalam perangkat mobile sehingga para siswa dapat menikmati suguhan informasi interaktif yang dipresentasikan secara audio-visual. Aplikasi ini menawarkan kesempatan bagi siswa untuk melatih dan merefleksi materi pembelajaran dalam rangka untuk mempersiapkan diri dengan memprediksi kemungkinan konsep-konsep atau kunci yang akan muncul dalam test.

Format ataupun mode yang tersedia di Quizlet menuntut siswa untuk menginterpretasi informasi secara ringkas dan padat, sekaligus menerjemahkan informasi yang tercantum di kumpulan flashcard tersebut dengan baik. Dengan demikian, dapat dikonfirmasikan bahwa siswa diberikan kesempatan untuk menggali sumber-sumber elektronik sebagai suplemen pembelajaran mereka di kelas.

Portabilitas perangkat mobile memberikan kecepatan proses sebagai media untuk mengakses Quizlet di luar kelas. Selanjutnya, para siswa dapat berbagi data dan berkolaborasi bersama teman sekelasnya. Hal ini mengindikasikan bahwa perangkat mobile dapat disesuaikan untuk menjalin keterlibatan di antara siswa sehingga mereka dapat bekerja sama menciptakan materi-materi pembelajaran yang dapat dibagikan ke semua siswa, bahkan ke seluruh dunia.

\section{Daftar Pustaka}

Aribowo, Eric Kunto. 2014. "iPadagogi dalam Praktik: Sebuah Model m-learning dalam Pembelajaran Bahasa" yang disajikan dalam Seminar Internasional dalam rangka Pertemuan Ilmiah Bahasa dan Sastra Indonesia PIBSI XXXVI dengan tema "Membangun Citra Indonesia di Mata Internasional melalui Bahasa dan Sastra Indonesia" pada 11-12 Oktober 2014 di Universitas Ahmad Dahlan Yogyakarta.

Ashcroft, R.J. dan Imrie A.C. 2014. "Learning Vocabulary with Digital Flashcard" dalam N. Sonda dan A. Krause (eds.), JALT 2013 Conference Proceedings. Tokyo:JALT.

Davie, Neil dan Tobias Hilber. 2015. "Mobile-Assisted Language Learning: Student Attitudes to Using Smartphones to Learn English Vocabulary" dalam nth International Conference Mobile Learning 2015. ISBN: 978-989-8533-36-4. hal. 70-78.

Doerr, John. 2014. "Smart Phones for Smart Kids" dalam Wall Street Journal, Eastern edition [New York, N.Y] 22 Aug 2014: A.11.

\footnotetext{
${ }^{10}$ Apabila terdaftar sebagai teacher yang berlangganan, guru dapat mengetahui rekaman kemajuan para siswa, kata-kata yang sering menjadi masalah untuk siswa, membandingkan data studi siswa sepanjang waktu sehingga kemampuan dan kebiasaan belajar siswa dapat diamati dengan lebih seksama.
} 
Foti, Megan K. dan Jomayra Mendez. 2014. "Mobile Learning: How Students Use Mobile Devices to Support Learning” dalam Journal of Literacy and Technology, Volume 15, Number 3: Desember 2014. ISSN: 1535o975. hal. $58-78$.

Kukulska-Hulme, Agnes dan John Taxler. 2005. Mobile Learning: A Handbook for Educators and Trainers. London dan New York: Routledge.

McQuiggan, Scott, Lucy Kosturko, Jamie McQuiggan, dan Jennifer Sabourin. 2015. Mobile Learning: A Handbook for Developers, Educators, and Learners. New Jersey: John Wiley \& Sons, Inc.

Srithar, Uma dan Dhivya Selvaraj. 2015. "Learning at Your Own Pace: M-Learning Solution for School Students" dalam International Journal of Information and Electronics Engineering, Vol. 5, No. 3, May 2015. DOI: 10.7763/IJIEE.2015.V5.533. hal. 216-224.

Vargas, Julie Marie. 2011. "Modern Learning: Quizlet in The Social Studies Classroom". Tesis: tidak diterbitkan. Kansas: Wichita State University. 